\title{
ESTUDO FITOQUÍMICO E ATIVIDADE ANTICOLINESTERÁSICA DE
}

\section{Passiflora spp.}

\author{
$\underline{\text { Priscila Pinto Costa }}^{1}$; Hugo Neves Brandão ${ }^{2}$; Clayton Queiroz Alves ${ }^{3}$; Diego Mota \\ da Costa $^{4}$ e Nicolás De Palma ${ }^{5}$ \\ 1. Bolsista PIBIC/CNPq, Graduando em Farmácia, Universidade Estadual de Feira de Santana, e-mail: \\ priiscilacosta@ hotmail.com \\ 2. Orientador, Departamento de Saúde, Universidade Estadual de Feira de Santana, e-mail: hugo@uefs.br \\ 3. Orientador, Departamento de Exatas, Universidade Estadual de Feira de Santana, e-mail: cleiroz@gmail.com \\ 4. Participante do projeto, Departamento de Saúde, Universidade Estadual de Feira de Santana, e-mail: \\ diegocost@live.com \\ 5. Participante do projeto, Departamento de Saúde, Universidade Estadual de Feira de Santana, e-mail: \\ nicolas.depalma@hotmail.com
}

PALAVRAS-CHAVE: estudo fitoquímico; atividade anticolinesterásica; Passiflora spp.

\section{INTRODUÇÃO}

O gênero Passiflora possui cerca de 400 espécies catalogadas, pertencente à família Passifloraceae que possui aproximadamente 16 gêneros e 650 espécies, sendo o gênero Passiflora considerado o mais importante (RAMOS et al., 2007). As espécies desse gênero como a Passiflora incarnata L., P. alata Curtis, $P$. coerulae L. e P. edulis Sims, por possuírem efeitos ansiolíticos e sedativos são muito utilizadas na Medicina tradicional da Europa e Américas (CARLINI, 2003).

Alguns compostos destacam o gênero, como os polifenóis, os ácidos graxos poliinsaturados, as fibras, entre outras substâncias. Ainda encontra-se desconhecido o mecanismo de ação da Passiflora spp., porém, sabe-se que a inibição da monoamina oxidase (MAO) e a ativação dos receptores de ácido gama-aminobutírico (GABA) podem estar envolvidos (KYNRIS; COLEMAN; ROTHESTEIN, 2009).

As espécies de Passiflora ou maracujá, como é conhecida popularmente no Brasil, é utilizada na sabedoria popular como ansiolítica, sedativa, diurética, antiinflamatória e analgésica, tendo seu uso mais acentuado como calmante. O extrato de suas folhas vem sendo muito utilizado em pesquisas. Em contra partida, segundo Vargas et al. (2007), existem poucos estudos farmacológicos de propriedades antiinflamatória com preparações de Passiflora. No Brasil, as espécies Passiflora alata e Passiflora edulis apresenta grande importância comercial além de estarem contidas na $5^{\text {a }}$ edição da Farmacopeia Brasileira (BRASIL, 2010).

Vale ressaltar que o gênero Passiflora está incluso na Relação Nacional de Plantas Medicinais de Interesse no SUS (RENISUS) de 2010, que contém uma lista de plantas medicinais que possuem produtos de interesse quanto ao desenvolvimento de novos fitoterápicos para uso da população, garantindo segurança e eficácia no tratamento de algumas doenças. As espécies do gênero contidas nessa relação são a $P$. incarnata, P. edulis e P. alata (ROBRE, 2015).

As plantas e os extrativos vegetais exibem grande importância no âmbito farmacêutico, visando à utilização das substâncias ativas como protótipos a serem utilizados no desenvolvimento de novos fármacos, bem como fonte de matérias-primas farmacêuticas, com finalidade de obtenção de medicamentos elaborados exclusivamente à base de extratos vegetais ou até mesmo adjuvantes (SCHENKEL; GOSMANN; PETROVICK, 2000), podendo ser avaliados em ensaios biológicos in vitro e submetidos a fracionamento biomonitorado. 
Os inibidores da Acetilcolinesterase são amplamente utilizados no tratamento da doença de Alzheimer, que é uma doença cerebral degenerativa e possui capacidade de comprometer a memória, a capacidade de raciocínio e comunicação (MARQUES et al., 2013). Assim, trabalhando diante dessa perspectiva utiliza-se uma técnica muito empregada para avaliar a Atividade Anticolinesterásica que consiste em adaptação (OZTURK, 2011) da metodologia que foi desenvolvida por Ellman (1961) e colaboradores.

Diante do pressuposto, entende-se a importância da pesquisa envolvendo as espécies de Passiflora, visto que há um incentivo do Ministério da Saúde quanto aos estudos com os gêneros presentes no RENISUS, envolvendo assim o gênero Passiflora. Além disso, apesar do interesse no que rege o estudo com plantas reconhecidas medicinalmente, ainda existem espécies do gênero Passiflora ainda não estudadas do ponto de vista fitoquímico.

\section{MATERIAL E MÉTODOS OU METODOLOGIA}

A espécie Passiflora spp. foi coletada na EMPRAPA situada na cidade de Cruz das Almas, nos meses de agosto e setembro de 2016, e identificada pelo especialista no gênero, Dr. Onildo Nunes de Jesus, curador do banco de gernoplasma de Passifloraceae. $\mathrm{O}$ material coletado passou por processo de secagem em estufa a $40^{\circ} \mathrm{C}$ até peso constante.

O material seco foi triturado em moinho de facas, no qual o pó resultante da trituração foi pesado em balança semi-analítica e a massa correspondente registrada para o cálculo de rendimento. Em seguida, passou por processo de extração por maceração, utilizando-se álcool metílico como solvente extrator. O filtrado da maceração foi concentrado em evaporador rotativo sob pressão reduzida para a obtenção do extrato bruto, que foi seco e submetido ao processo de partição através de um funil de separação, utilizando solventes em ordem crescente de polaridade (hexano, clorofórmio e acetato de etila) para a obtenção dos extratos semipurificados.

O fracionamento dos extratos obtidos do caule de Passiflora spp. foi realizado por Cromatografia em Coluna (CC) no qual foi utilizada sílica gel 60 (MERCK) como fase estacionária e como fase móvel para o extrato clorofórmico utilizou-se clorofórmio e metanol em ordem crescente de polaridade, resultando em diferentes frações e para o extrato hexânico utilizou-se hexano e acetato, em ordem crescente de polaridade, os quais também resultaram em diferentes frações.

O extrato clorofórmico, acetato de etila e hexânico do caule e das folhas de Passiflora spp. foram submetidos ao teste de Atividade Anticolinesterásica in vitro. Essa técnica, muito empregada para avaliar a capacidade de substâncias em inibir a enzima acetilcolinesterase (AChE), consiste em uma adaptação (OZTURK, 2011) da metodologia que foi desenvolvida por Ellman (1961) e colaboradores. Para a realização do teste foram adicionados em uma placa de 96 poços $140 \mu \mathrm{L}$ de solução tampão e, em seguida, $20 \mu \mathrm{L}$ da enzima $\mathrm{AChE}(5 \mathrm{U} / \mathrm{mL})$ e $20 \mu \mathrm{L}$ da amostra ou padrão diluídos em etanol. Posteriormente foram acrescentados $10 \mu \mathrm{L}$ de DTNB $(10 \mathrm{mM})$ e após 15 minutos de incubação à temperatura ambiente foi realizada a primeira leitura em $405 \mathrm{~nm} \mathrm{em}$ leitor de microplacas. Após a adição $10 \mu \mathrm{L}$ de ATCI $(15 \mathrm{mM})$, foi realizada uma nova leitura. Assim, as reações foram acompanhadas até o tempo final de 30 minutos. $\mathrm{O}$ resultado foi comparado com padrão comercial Eserina (Fisiostigmina) na concentração de $500 \mu \mathrm{Mol}$. As análises foram realizadas em triplicata.

A fração PCH04C do foi enviada para aquisição dos espectros de Ressonâncias Magnética Nuclear por apresentarem-se puras quando reveladas em CCD, bem como a fração CFPM4D2C3, as quais ainda estão em processo de análise para se identificar qual possível substância foi isolada. 


\section{RESULTADOS E/OU DISCUSSÃO}

Após preparo e secagem do extrato do caule de Passiflora spp., foi obtida uma massa total de extrato bruto de 50,45g resultando um rendimento de $3,30 \%$. O extrato metanólico bruto do caule foi particionado com solventes de diferentes polaridades, resultado nos extratos hexânico $(5,016 \mathrm{~g})$, clorofórmico $(3,453 \mathrm{~g})$ e acetato de etila $(1,015 \mathrm{~g})$, além do extrato bruto das folhas com massa de $132,94 \mathrm{~g}$ e o rendimento de $5,90 \%$, também particionado obtendo-se os extratos hexânico com massa de 24,578g, clorofórmico com 17,595g e acetato de etila com 1,435g.

Os extratos foram escolhidos previamente para fracionamento após serem analisados por Cromatografia em Camada Delgada, logo, os extratos escolhidos (clorofórmico e hexânico do caule, bem como o clorofórmico e acetato das folhas) foram os que apresentaram melhor resolução em CCD. As frações enviadas para análise em RMN ainda se encontram em análise.

Como uma das mais significantes mudanças na área de produtos naturais nos últimos anos, tem-se a avaliação biológica, no qual o entendimento dos mecanismos da doença juntamente com o aumento de testes com receptores e enzimas disponíveis permitiu desenvolver sistemas mais eficientes de bioensaios (TREVISAN; MACEDO, 2003). A determinação da Atividade Anticolinesterásica dos extratos foi realizada através dos cálculos de acordo com a fórmula $\% \mathrm{IAChE}=[(\Delta$ Controle negativo $-\Delta$ Amostra) / $\Delta$ Controle] x 100 , onde $\Delta$ do controle negativo equivale a variação final menos a variação inicial do controle negativo, ou seja, sem a presença do inibidor, menos a variação com a presença do inibidor.

Através dos cálculos de atividade realizados foi possível perceber que os extratos de Passiflora spp. do caule apresentaram maior porcentagem inibitória da acetilcolinesterase quando comparados com os extratos das folhas, visto que os extratos hexânico, clorofórmico e acetato de etila do caule inibiram 11,76\%, 12,02\% e 21,12\% respectivamente, já os extratos das folhas como o hexânico inibiu uma porcentagem de $10,66 \%$, do extrato clorofórmico não foi possível detectar inibição e o extrato acetato de etila inibiu 3,74\% (Gráfico 01).

Entretanto, os valores obtidos referentes à inibição da acetilcolinesterase são considerados baixo, visto que os mesmos não atingiram nem $50 \%$ de inibição, principalmente quando comparado ao padrão comercial que é a Eserina, com 97,51\% de atividade inibitória. Contudo, faz-se necessário a realização de novos testes tanto com as frações obtidas por Cromatografia em Coluna desses extratos, quanto com as substâncias isoladas.

\section{Gráfico 01: Porcentagem inibitória da acetilcolinesterase dos extratos obtidos da espécie Passiflora spp.}

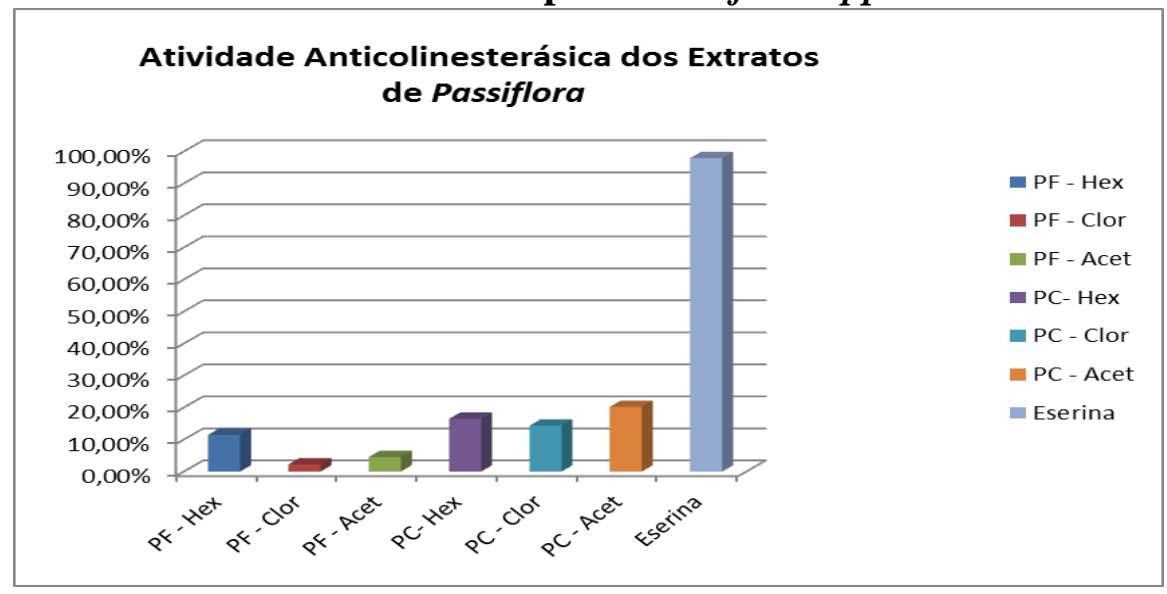




\section{CONCLUSÃO}

Através da análise dos extratos no teste de atividade anticolinesterásica foi possível perceber que os mesmos apresentaram atividade inibitória frente à acetilcolina, mesmo que essa porcentagem não tenha chegado a 50\%, percebeu-se também que os extratos oriundos do caule de Passiflora spp. apresentaram maior atividade inibitória quando comparados aos extratos das folhas.

Dessa maneira, com base nos resultados alcançados nos experimentos foi possível analisar os constituintes químicos presentes na espécie Passiflora spp. As substâncias isoladas não puderam ser testadas, pois ainda encontram-se na central de análises de RMN. Contudo, este trabalho contribuiu para a quimiotaxonomia das espécies do gênero Passiflora.

\section{REFERÊNCIAS}

BRASIL, Farmacopéia Brasileira. Agência Nacional de Vigilância Sanitária.

Farmacopéia Brasileira. 5 ed. v. 2. Brasília, 2010.

CARLINI, E. A. Plants and the central nervous system.Pharmacol.Biochem.Behav., v. 75,2003 . p. $501-512$

ELLMAN, G. L., COURTNEY, K. D., ANDRES, V., FEATHERSTONE, R. M. A new and rapid colorimetric determination of acetylcholinesterase activity, Biochem.

Pharmacol. 7, 1961. p. 88-95

KYNRIS, E.; COLEMAN, E.; ROTHESTEIN, E. Natural Remedies for Anxiety

Disorders. Depress. Anxiety., v. 26, 2009. p. 259-265

ZERAIK, M.L. et al. Maracujá: um alimento funcional? Rev. Bras. Farmagn., v.20, n.3, 2010. p.459-471

MARQUES, T. H. C. et al. Atividade anticolinesterásica e perfil químico de uma fração cromatográfica ativa do extrato etanólico das flores Bellis perennis

L.(Asteraceae). Química Nova, v. 36, n. 4, 2013. p. 549-553

ÖZTÜRK, H., KOLAK, U., MERIC, C., Antioxidant, Anticholinesterase and

Antibacterial Activities of Jurinea consanguinea DC, Records of Natural Products 5:1, 2011. p. 43-51

RAMOS, A. T. et al.Uso de Passiflora edulis f. flavicarpana redução do colesterol.Rev. Brasileira de Farmacognosia. v. 17, Paraíba, 2007. p. 592-597

ROBRE, D. D.; SCALON FILHO, H. Recomendações terapêuticas de cinco plantas autorizadas pelo sus. Anais do semex, v. 3, n. 3, 2015.

SCHENKEL, E. P.; GOSMANN, G.; PETROVICK, P. R. Produtos de origem vegetal e o desenvolvimento de medicamentos. In: SIMÕES, C. M. O. Farmacognosia: da

planta ao medicamento. 2. ed. rev. Porto Alegre: Florianópolis: Ed. da UFRGS Ed. da UFSC, 2000.

TREVISAN, M. T.; MACEDO, F. V. V. Seleção de plantas com atividade anticolinesterase para tratamento da doença de Alzheimer. Rev. Quim. Nova, Vol.26, 2003. p. 301-304.

VARGAS, A. J.; GEREMIAS, D. S.; PROVENSI, G.; FORNARI, P. E.; REGINATTO, F. H.; GOSMANN, G.; SCHENKEL, E. P.; FRODE, T. S. Passiflora alata and Passiflora edulis spray-dried aqueous extracts innibit inflammation in mouse model of pleurisy. Fitoterapia. v. 78, 2007. p. 112-119 